\title{
28 Research Square

\section{A systematic review and meta-analysis on global prevalence of infectious diseases in backyard chicken in the recent two decades}

T. R. Kannaki ( $\nabla$ trkannaki@gmail.com )

ICAR-Dircetorate of Poultry Research

\section{E. Priyanka}

ICAR-Directorate of Poultry Research

Santosh Haunshi

ICAR-Directorate of Poultry Research

Madhuri Subbiah

National Institute of Animal Biotechnology

\section{Systematic Review}

Keywords: Backyard chicken, meta-analysis, systematic review, disease prevalence

Posted Date: August 24th, 2021

DOI: https://doi.org/10.21203/rs.3.rs-778051/v1

License: @ (i) This work is licensed under a Creative Commons Attribution 4.0 International License. Read Full License 


\section{Abstract}

Backyard poultry is evolving as a fast-growing sector in recent times across the world. Apart from providing nutritional security, and livelihood to marginalized sector, also fulfils the demand for organic and welfare meat and eggs. However, the productivity is often challenged by incidences of diseases due to poor biosecurity and lack of vaccination. In this study, systematic review and meta-analysis were performed on the global prevalence of infectious diseases in backyard chickens. A total of 22 bacterial, viral, parasitic and fungal diseases were reported from 55 publications between 2000 and 2020 worldwide. Viral diseases were the most reported followed by bacterial and parasitic diseases. 61 out of 91 studies from 55 publications investigated seven major diseases: Avian influenza (Al), Newcastle disease (ND), infectious bronchitis (IB), Mycoplasma gallisepticum (MG), Mycoplasma synoviae (MS), Salmonella infection, and infectious laryngotracheitis (ILT). The overall pooled prevalence estimate for all the diseases worldwide was 33\% (95\% confidence interval (Cl): 28-38). The pooled estimates for most reported viral diseases Al and ND were 12.5\% (95\% Cl: 7-18) and 30\% Cl: 19-43), respectively. IBD (71\% Cl: $13-100)$, MS (76\% Cl: $67-85)$ and helminth infestations (72\% Cl: $44-93)$ were the highly prevalent diseases among viral, bacterial and parasitic infections, respectively. The continent wise pooled prevalence ranged from 17-32\%. The present results will help in devising the best possible strategies to minimize the disease risk for commercial poultry and humans as well as for improving the productivity of backyard poultry farming.

\section{Introduction}

Backyard poultry or small-holder poultry systems are characterized by their small flock size (generally $<50$ ), germplasm of various genetic backgrounds from native chicken breeds/ local ecotypes/ crossbreeds, mostly extensive / free-range system of rearing with no/ limited biosecurity and vaccination practices. Interestingly, despite commercial poultry being the major organized sector serving the protein need of the growing population, backyard poultry accounts for $80 \%$ of the total stock in most of the developing countries. Backyard poultry is increasingly becoming popular in developed countries also. The trend towards backyard poultry in developed countries is driven by consumer awareness and demand for organic, sustainable, and welfare eggs and meat (Bray et al., 2017).

Although backyard poultry is proving livelihood and nutritional security to the marginalized farming communities especially in developing countries, the disease threat posed by the unorganized sector to the commercial poultry is significant. Backyard poultry plays an important role in potentially transmitting pathogens to commercial poultry as well as to wild birds (Pollock et al., 2012). FAO has identified small holder livestock systems as large facilitators of infectious diseases (Slingenbergh, 2013). Moreover, their role also has been implicated in the transmission of certain zoonotic pathogens such as Salmonella, Campylobacter and influenza to humans. Systematic studies on the disease prevalence of the backyard poultry sector are absolutely lacking. Although the backyard poultry sector is expanding at a faster rate, the regulatory, health care and extension systems are not developing to support the same. In this context, we investigated the studies on the prevalence of various diseases in backyard poultry worldwide during the last two decade and analysed their prevalence and implications.

\section{Materials And Methods}




\subsection{Literature search}

A systematic search was conducted in three electronic search engines including 'PubMed', 'Google Scholar' and 'Biomed' databases from 2000 to 2020 . The search terms 'backyard poultry', 'disease' and 'prevalence' were used in combinations for systematic electronic searches. Articles were extracted individually by two authors to avoid any bias. All the searches, search strategy, inclusion criteria, data extraction and analysis were performed according to the 'Preferred Reporting Items for Systematic Reviews and Meta-Analyses (PRISMA) protocol recommended by the Cochrane library (Page and Moher, 2017).

\subsection{Inclusion Criteria}

The inclusion criteria were as follows: (i) Study design- Cross-sectional studies (ii) Sampling procedure- random sampling (iii) timeframe- 2000 to 2020 (iv) language- English (v) Full article available for data extraction (vi) Diagnostic method and sample data mentioned (vii) Published in peer-reviewed journal (viii) studies only on backyard chicken. Retrospective studies, field outbreak studies, experimental infection studies, case reports and review articles were excluded. Studies that investigated other backyard poultry species like turkey, duck, goose and other migratory birds were also excluded. Only those data on backyard chickens were included for analysis.

\subsection{Data extraction}

A template was prepared to collect and organize the information from selected publications. Data including author name, year of publication, country, total sample size, positives, a diagnostic method used, disease investigated were extracted manually from selected publications and entered into a Microsoft Excel sheet (2016, Microsoft Corporation, WA). Selected articles were stratified based on the individual disease-wise and continentwise in separate documents. All the concerns about the inclusion of a study were resolved by discussion until consensus upon any disagreement.

\subsection{Quality assessment}

Quality assessment was performed by two authors independently on a fixed rating scale (Kuralayanapalya et al., 2019). The scale includes evaluation of study selection, comparability and outcome. With each section assigned a maximum score of 5, 3 and 2 respectively. Studies having a minimum score of 3 were included in the analysis.

\subsection{Meta-analysis}

Extracted data was organized in Microsoft Excel and stratified based on individual disease-wise and continentwise. Descriptive statistics for the number of studies per year, diagnostic method-wise and continent-wise were performed to understand the spatial and temporal distribution of the infectious and parasitic diseases in backyard poultry world-wide over the period of time. Meta-analysis for the prevalence of infectious and parasitic diseases in backyard chicken data was performed in the R studio of R open-source software (Version 3.4.3). The inbuilt software packages 'Metafor', 'MetaProp' and 'Meta R' were used for the analysis. A random effect model was used to calculate the pooled prevalence in the data using the package. Data was stratified both based on individual disease-wise and continent-wise. DerSimonian and Laird random effect model, Jackson method and Freeman-Tukey double arcsine transformation methods were used for deriving the pooled prevalence at $95 \%$ 
confidence interval (CI) (DerSimonian and Laird, 1986). Cochran's Q-statistics, $\mathrm{I}^{2}$ and P values were computed to measure the heterogeneity among the studies. Between the study variance was assessed by $\tau^{2}$. The effective sizes and weighted average of individual studies were given in forest plots. Funnel plots were generated for data to analyse the publication bias (Egger et al., 1997).

\section{Results}

\subsection{Study details}

A total of 671 studies were identified through electronic searches of 3 databases using the keywords. Out of the total 671 studies, 445 were removed due to duplication, the remaining 324 records were screened. After reviewing the full text and applying the inclusion criteria, only 55 articles were found eligible for inclusion for meta-analysis. The sequence of searches, selection and exclusion of publications are depicted in the flowchart (Fig. 1). Report on each disease from a publication is considered as individual study. The selected 55 publications reported 91 studies on 22 different infectious and parasitic diseases of backyard chicken from the total sample size of $1,02,643$. All the studies included $(n=55)$ were cross-sectional studies with a random sampling model. The reported type of chicken includes native breeds, local ecotypes, cross-breds and improved varieties suitable for free-range and backyard rearing. The mean sample size of the 91 studies was $1127 \pm 339$.

61 out of 91 studies (67\%) from 55 publications reported seven major diseases viz., Avian influenza (Al), Newcastle disease (ND), infectious bronchitis (IB), Mycoplasma gallisepticum (MG), Mycoplasma synoviae (MS), Salmonella infection and infectious laryngotracheitis (ILT). Viral diseases were the most reported $62.6 \%$ (57/91) followed by bacterial 21.9\% (20/91) and parasitic \& fungal diseases 15.3\% (14/91). Among the viral diseases, Al -19.7\% (18/91) and ND- 17.5\% (16/91) were mostly reported followed by IB-9.89\% (9/91) and others. Among the bacterial diseases, Salmonella-5.4\% (5/91) and MS-5.4\% (5/91) were reported comparatively higher than others (Fig. 2). Coccidiosis- 4.3\% (4/91) is relatively reported higher than others among the parasitic and fungal diseases. Few diseases including chicken infectious anemia (CIA), West Nile virus, Leucocytozoan, Ectoparasite infestation and Histomoniasis were reported by single studies each. Continent -wise analysis revealed that the African continent reported more studies 34\% (19/55) followed by Asia 23\% (13/55) (Fig. 3). Out of 55 publications, 41 reported the prevalence of a single disease followed by 7 publications on dual diseases and 3 publications on 3 to -4 diseases. A total of 4 publications reported 6 to -10 diseases (Fig. 3). Among the diagnostic methods employed for prevalence studies, serology was the most used among the studies (17/55) followed by molecular methods including PCR and others (12/55). 15 publications out of 55 employed more than one diagnostic method for the disease diagnosis (Fig. 3).

\subsection{Temporal distribution of studies}

Analysis of publications made on the prevalence of diseases in backyard chicken revealed that $90 \%$ of the publications were made during the recent decade, $2010-20$. Only $10 \%$ of the publications were made during the previous decade, 2000-10. The publication trend is depicted in Fig. 4. Although the pattern of publication over the years is fluctuating, the overall trend is increasing over the period as indicated by the trendline of $\mathrm{Y}=0.33 \mathrm{x}$ -0.92 . 


\subsection{Meta-analysis of pooled prevalence}

Systematic review and meta-analysis of pooled overall prevalence of infectious and parasitic diseases in backyard chicken are estimated to be $30 \%$ worldwide (95\% confidence interval (Cl): $28-38$ ). The analysis of disease-wise pooled prevalence for 22 diseases including 9 viral diseases, 6 bacterial diseases and 7 parasitic and fungal infestations ranged from 1.5 to $96 \%$. The disease-wise pooled prevalence is presented in Table 1 . For 3 bacterial and 2 parasitic diseases, only one study was available, hence analysis could not be performed. Among the viral diseases, Al and ND are the most investigated diseases and pooled prevalence are $12.5 \%$ and $30.8 \%$, respectively. The graphical representation of data on the prevalence of $\mathrm{Al}$ and ND in backyard chicken were depicted in forest plots (Figs. 5 \& 6). Among the viral diseases, infectious bursal disease (IBD) - at 71\% followed by avian encephalomyelitis (AE) -at $65 \%$ were having more prevalence worldwide. Among the bacterial diseases, MG and MS had a higher pooled prevalence of $60 \%$ and $76 \%$, respectively. Salmonella and Campylobacter infections had pooled prevalence of 23 and $36 \%$, respectively. Helminth infestation was the most prevalent $(72 \%)$ among the parasitic and fungal diseases.

Continent-wise pooled prevalence calculated from the data of selected studies is presented in Table 2. A relatively higher prevalence of diseases was observed in Asia (32\%) followed by Oceania (30\%), Europe (26\%), Africa (24\%), North America (23\%) and South America (17\%). Heterogeneity of the studies indicated by $\mathrm{I}^{2}, \mathrm{\tau}^{2}$ and $P$ values analysed by individual disease wise and continent wise are presented in table 1 and 2, respectively. The values of $\mathrm{I}^{2}$ statistics show that there is a high level of heterogeneity between studies.

\subsection{Test of publication bias}

The funnel plots were generated for individual disease-wise and continent-wise for the data. Inspection of the funnel plot showed that the majority of the studies were scattered in the funnel plot with fair symmetry. Funnel plots for the continents are presented in Fig. 7.

\section{Discussion}

A systematic review and meta-analysis of publications on the prevalence of infectious and parasitic diseases of backyard chicken throughout the world was carried out. The present study reviewed 91 studies from selected 55 publications during the period 2000-2020 worldwide and reported 22 different diseases from a total of 1,02,643 samples. The worldwide overall pooled prevalence was analysed as $33 \%$ for all the diseases together.

Among the reported diseases, Mycoplasmosis (60-76\%), helminth infestation (72\%), infectious bursal disease (IBD - 71\%), avian encephalomyelitis (AE-65\%), infectious bronchitis (IB-45\%), Coccidiosis (31\%) and Newcastle disease (ND-30\%) were analysed as the most prevalent diseases worldwide. Although high prevalence was reported for Orinithobacterium rhinotracheale (ORT - 96\%), Leucocytozoan (69\%) and chicken infectious anemia (CIA - 53\%), the number of studies was meagre. Mycoplasma gallisepticum (MG) and Mycoplasma Synoviae (MS) are commonly found in backyard chickens and the most notable bacterial pathogens that have spread from backyard chicken to wild birds (Ayala et al., 2020). Avian influenza (Al) was the most reported disease worldwide followed by Newcastle disease (ND) in backyard poultry in the present meta-analysis. Al and ND are the two major RNA virus disease that are creating major havoc and therefore, important to backyard poultry. Earlier a meta-analysis study also reported that interface between the free-living bird and poultry was the most 
highly reviewed interface among the emerging pathogens particularly with concern to Al (Wiethoelter et al., 2015). The pooled prevalence of $9 \%$ and $23 \%$ were reported for Al and ND recently from duck population worldwide (Patil et al., 2021). The association of high risk of contracting the avian influenza viruses to humans was linked to live markets handling the sick and infected chicken (Fournié et al., 2017). Seropositivity for Al in backyard poultry is often associated with their proximity to waterfowls/ water bodies, migratory/wild birds, live bird trading, etc. Different policies like vaccination, strict biosecurity, stamping out, etc. are followed for the control of Al by different countries. Simple intervention strategies like use of disinfectant during cleaning, avoiding the proximity to water bodies significantly reduce the risk of seropositivity of Al (Paul et al., 2011; Madsen et al., 2013).

ND has become an endemic disease in many developing countries. NDV has been isolated from a wide range of avian host, almost all bird species are susceptible to the virus replication, shedding and transmission posing risk as a reservoir for commercial poultry (Alexander et al., 2004). While commercial poultry receives at least 5-to 8 vaccine shots for ND control, the backyard counterpart practically receives none. Present study revealed the prevalence of $30 \%$ in backyard chicken for ND. Earlier studies also reported $34 \%$ and $40 \%$ seropositivity in unvaccinated backyard chickens in Vietnam and Iran, respectively (Vui et al., 2002; Saadat et al., 2014). Nevertheless, backyard chicken is considered as potential source of reservoir for pathogen spill over including ND and spread to wild birds (Ayala et al., 2020).

Salmonella and Campylobacter are of public health concern and their prevalence worldwide as 5.4 and $43 \%$, respectively. Similar higher level of pooled prevalence of 34\% Campylobacter infection was reported earlier in animals (Pintar et al., 2015). Moreover, backyard chickens are a reservoir of Campylobacter jejuni strains and a potential source of $C$. jejuni infection for humans (Pohjola et al., 2016). The high prevalence of Campylobacter in backyard poultry in the present study is of major public health concern, although the reports were from only two countries. Pooled prevalence of $67 \%$ for ND and $37.4 \%$ for Toxoplasma gondii were reported from African countries (Miguel et al., 2013; Tonouhewa et al., 2017). Although the studies on the diseases of backyard poultry are increasing over recent times, the rate is not matching with the growth of the sector emphasising the need for more research studies.

The statistical indicators including $\mathrm{I}^{2}$ and $\mathrm{\tau}^{2}$ indicated higher heterogeneity among most of the studies. Similarly, a high level of heterogeneity was observed among the studies reporting the disease prevalence by various authors (Asfaw et al., 2019; Patil et al., 2021). Various factors like different breeds, management practices, geographical variations and diagnostic methods are speculated for the possible heterogeneity observed (Higgins and Green, 2008).

Biosecurity and vaccination are the two crucial practices to mitigate disease outbreaks from the poultry flocks. However, backyard flocks are less often subjected to any biosecurity measures and only $3-10 \%$ of the backyard flocks are vaccinated against common poultry pathogens (Garber et al., 2007). The high prevalence of diseases in backyard poultry worldwide may be attributed to these factors. Backyard chickens serve as a biosecurity risk to commercial poultry and act as a reservoir for spillover poultry pathogens from wild birds as well as commercial poultry (Ayala et al., 2020). Practices such as free-range rearing, proximity to wild birds, water bodies, live bird markets, etc. are attributed for the pathogen transmission between backyard chicken to commercial poultry and wild birds. Moreover, the backyard poultry owners lack adequate knowledge on hygienic management practices specifically in carcass disposal and cleaning the premises, identifying the sick birds, 
inadequate veterinary care, limited access to health care and disease management, etc. and these factors potentiate the risk.

\section{Conclusion}

In conclusion, the results of the present study will help in prioritizing the focus on the important diseases of concern in backyard poultry and devising the best possible strategies to minimize the risk for commercial poultry and humans as well as for improving the productivity of the backyard poultry farming.

\section{Declarations}

\section{Acknowledgements}

The authors acknowledge the Director, ICAR-DPR, Hyderabad for the support.

\section{Conflict of interest}

The authors declare that there is no conflict of interest.

\section{Funding statement}

The author(s) received no specific funding for this work.

\section{Data availability}

The data underlying the results presented in the study are available from the published articles given in supplementary file 2 .

\section{References}

Alexander, D. J., Bell, J.G., and G.R. Alders 2004. Technology Review: Newcastle Disease, with Special Emphasis on its Effect on Village Chickens. Rome: FAO.

Asfaw, Yohannes, Ameni, Gobena, Medhin, Girmay, Alemayehu, Gezahegn, Wieland, and Barbara. 2019. Infectious and parasitic diseases of poultry in Ethiopia: a systematic review and meta-analysis. Poult. Sci. 98:6452-6462.

Ayala, A. J., Yabsley, M. J., and S.M. Hernandez. 2020. A Review of Pathogen Transmission at the Backyard Chicken-Wild Bird Interface. Front. Vet. Sci. 7:539925.

Bray, H. J., and Ankeny, A.R. 2017. Happy chickens lay tastier eggs: motivations for buying free-range eggs in Australia. Anthrozoös. 30:213-226.

DerSimonian, R., and N. Laird 1986. Meta-analysis in clinical trials. Control. Clin. Trials. 7:177-188 
Egger, M., Smith, G.D., Schneider, M., and C. Minder. 1997. Bias in meta-analysis detected by a simple, graphical test. Br. Med. J. 315: 629-634.

Fournié, G., Høg, E., Barnett, T., Pfeiffer, D.U., and P. A. Mangtani. 2017. Systematic Review and Meta-Analysis of Practices Exposing Humans to Avian Influenza Viruses, Their Prevalence, and Rationale. Am. J. Trop. Med. Hyg. 97(2):376-388.

Garber, L., Hill, G., Rodriguez, J., Gregory, G. and L. Voelker. 2007. Non-commercial poultry industries: surveys of backyard and gamefowl breeder flocks in the United States. Prev. Vet. Med. 80(2-3):120-128.

Higgins, J. P. T., and S. Green, eds. 2008. Cochrane Handbook for Systematic Reviews of Interventions. John Wiley and Sons, Ltd, Chichester.

Kuralayanapalya, S.P., Patil, S.S., Hamsapriya, S., Shinduja, R., Roy, P. and Amachawadi, R.G. 2019. Prevalence of extended-spectrum beta-lactamase producing bacteria from animal origin: A systematic review and metaanalysis report from India. PLoS One. 14(9):e0221771.

Madsen, J.M., Zimmermann, N.G., Timmons, J. and N.L. Tablante. (2013). Avian influenza seroprevalence and biosecurity risk factors in Maryland backyard poultry: a cross-sectional study. PLoS One. 8(2):e56851.

Miguel, E., V. Grosbois, C. Berthouly-Salazar, A. Caron, J. Cappelle, and F. Roger. 2013. A meta-analysis of observational epidemiological studies of Newcastle disease in African agrosystems, 1980-2009. Epidemiol. Infect. 141:1117-1133.

Page, M. J., and D. Moher. 2017. Evaluations of the uptake and impact of the Preferred Reporting Items for Systematic reviews and Meta-Analyses (PRISMA) Statement and extensions: a scoping review. Syst. Rev. 6:263.

Patil, Sharanagouda, Rajamani, Shinduja, Suresh, Kuralayanapalya, Phukan, Sulekha, Kumar, Sachin, Sengupta, Pinaki, Amachawadi, Raghavendra, Raut, Ashwin, Roy, Parimal \& Syed, Asad, Marraiki, Najat, Elgorban, Abdallah, Al-Harthi, Helal, Bahkali, Ali, Shivamallu, Chandan and Prasad, Shiva. 2021. A systematic review and metaanalysis on the prevalence of infectious diseases of Duck: A world perspective. Saudi Journal of Biological Sciences. 10.1016/j.sjbs.2021.05.034.

Paul, M., Wongnarkpet, S., Gasqui, P., Poolkhet, C., Thongratsakul, S., Ducrot, C. and F. Roger. 2011. Risk factors for highly pathogenic avian influenza (HPAI) H5N1 infection in backyard chicken farms, Thailand. Acta Trop. 118(3):209-216.

Pintar, K. D. M., T. Christidis, M. K. Thomas, M. Anderson, A. Nesbitt, J. Keithlin, B. Marshall, and F. Pollari. 2015. A systematic review and meta-analysis of the Campylobacter spp. prevalence and concentration in household pets and petting zoo animals for use in exposure assessments. PLoS One. 10:12

Pohjola, L., Nykäsenoja, S., Kivistö, R., Soveri, T., Huovilainen, A., Hänninen, M.L., and M. Fredriksson-Ahomaa. 2016. Zoonotic Public Health Hazards in Backyard Chickens. Zoonoses Public Health. 63(5):420-430.

Pollock, S. L., Stephen, C., Skuridina, N. and T. Kosatsky. 2012. Raising chickens in city backyards: the public health role. J. Community Health. 37(3):734-742. 
Saadat, Y., Ghafouri, S.A., Tehrani. F. and A.G. Langeroudi. 2014. An active serological survey of antibodies to newcastle disease and avian influenza (H9N2) viruses in the unvaccinated backyard poultry in Bushehr province,Iran, 2012-2013. Asian Pac. J. Trop. Biomed. May;4(Suppl 1): S213-6.

Slingenbergh, J. World livestock 2013: changing disease landscapes. In: Slingenbergh J, editor. Rome: Food and Agriculture Organization of the United Nations (FAO).

Tonouhewa, A. B. N., Y. Akpo, P. Sessou, C. Adoligbe, E. Yessinou, Y. G. Hounmanou, M. N. Assogba, I. Youssao, and S. Farougou. 2017. Toxoplasma gondii infection in meat animals from Africa: systematic review and metaanalysis of sero-epidemiological studies. Vet. World. 10:194-208.

Vui, T.Q., Lohr, J., Kyule, M. and K. Zessin 2002. Baumann M. Antibody levels against newcastle disease virus, infectious bursal disease virus and avian influenza virus in rural chickens in Vietnam. Int. J. Poult. Sci.1:127132.

Wiethoelter, A.K., Beltrán-Alcrudo, D., Kock, R. and S.M. Mor. 2015. Global trends in infectious diseases at the wildlife-livestock interface. Proc Natl Acad Sci U S A. 112(31):9662-9667.

\section{Supplementary Data}

Supplementary data available online at the publisher site.

Supplementary file 1: Studies and details included for Meta-analysis

Supplementary file 2: References of publications included in the study

Supplementary file 3: Quality assessment of the studies included in meta-analysis

Supplementary file 4: PRISMA statement

\section{Tables}

Table 1. Number and proportion of studies sorted by disease-wise and their pooled prevalence.

*Total no. of studies: 91 from 55 publications selected for meta-analysis. Al: Avian influenza, ND-Newcastle disease, IB-Infectious bronchitis, ILT-Infectious laryngotracheitis, IBD-Infectious bursal disease, CIA-Chicken infectious anemia, MG-Mycoplasma gallisepticum, MS-Mycoplasma Synoviae, ORT-Ornithobacterium rhinotracheale.

Table 2. Continent wise number of publications, proportions and pooled disease prevalence. 


\begin{tabular}{|c|c|c|c|c|c|c|c|c|}
\hline $\begin{array}{l}\text { Type of } \\
\text { studied } \\
\text { diseases }\end{array}$ & Disease & $\begin{array}{l}\text { No. of } \\
\text { studies }\end{array}$ & $\begin{array}{l}\text { Proportion } \\
\text { of studies } \\
(\%) *\end{array}$ & $\begin{array}{l}\text { Sample } \\
\text { size }\end{array}$ & $\begin{array}{l}\text { Pooled } \\
\text { prevalence } \\
(95 \% \mathrm{Cl})\end{array}$ & $\mathrm{I}^{2}(\%)$ & $\tau^{2}$ & $P$ \\
\hline \multirow[t]{9}{*}{$\begin{array}{l}\text { Viral } \\
\text { diseases }\end{array}$} & $\mathrm{Al}$ & 18 & 19.7 & 63783 & $\begin{array}{l}12.5(7.8- \\
18)\end{array}$ & 99.7 & 0.026 & 0 \\
\hline & ND & 16 & 17.5 & 13838 & $\begin{array}{l}30.8(19- \\
43)\end{array}$ & 99.6 & 0.071 & 0 \\
\hline & IB & 9 & 9.89 & 7298 & $\begin{array}{l}45.6(32- \\
59)\end{array}$ & 98.8 & 0.041 & 0.0001 \\
\hline & ILT & 4 & 4.39 & 1384 & $\begin{array}{l}30.8(7.7- \\
60)\end{array}$ & 99.2 & 0.093 & 0.0001 \\
\hline & IBD & 3 & 3.29 & 1007 & $\begin{array}{l}71.3(13- \\
100)\end{array}$ & 99.9 & 0.600 & 0.0001 \\
\hline & Metapneumovirus & 3 & 3.29 & 728 & $\begin{array}{l}30.8(7.7- \\
60.7)\end{array}$ & 99.2 & 0.093 & 0.0001 \\
\hline & $\begin{array}{l}\text { Avian } \\
\text { encephalomyelitis }\end{array}$ & 2 & 2.19 & 557 & $\begin{array}{l}65.8(8.4- \\
100)\end{array}$ & 99.3 & 0.215 & 0.0001 \\
\hline & CIA & 1 & 1.09 & 457 & 53.17 & - & - & - \\
\hline & West Nile virus & 1 & 1.09 & 985 & 4.06 & - & - & - \\
\hline \multirow[t]{6}{*}{$\begin{array}{l}\text { Bacterial } \\
\text { diseases }\end{array}$} & MG & 5 & 5.49 & 1309 & $\begin{array}{l}60.6(45- \\
75)\end{array}$ & 96.4 & 0.028 & 0.0001 \\
\hline & MS & 4 & 4.39 & 775 & $\begin{array}{l}76.9(67- \\
85)\end{array}$ & 84.4 & 0.009 & 0.0002 \\
\hline & Salmonella & 5 & 5.49 & 5118 & $\begin{array}{l}5.4(1.8- \\
10.7)\end{array}$ & 97.4 & 0.011 & 0.0001 \\
\hline & Pasteurella & 2 & 2.19 & 725 & $\begin{array}{l}32.75(0- \\
90)\end{array}$ & 99.7 & 0.212 & 0.0001 \\
\hline & ORT & 2 & 2.19 & 501 & $\begin{array}{l}96.02(94- \\
97)\end{array}$ & 0 & 0 & 0.70 \\
\hline & Campylobacter & 2 & 2.19 & 670 & $43(17-71)$ & 98.2 & 0.042 & 0.0001 \\
\hline \multirow{7}{*}{$\begin{array}{l}\text { Parasitic } \\
\text { and } \\
\text { fungal } \\
\text { disease }\end{array}$} & Coccidiosis & 4 & 4.39 & 1195 & $31(5-65)$ & 99.1 & 0.124 & 0.0001 \\
\hline & $\begin{array}{l}\text { Helminth } \\
\text { infection }\end{array}$ & 3 & 3.29 & 432 & $72(44-93)$ & 96.6 & 0.061 & 0.0001 \\
\hline & Toxoplasmosis & 2 & 2.19 & 605 & $\begin{array}{l}23.9(0- \\
70)\end{array}$ & 98.6 & 0.120 & 0.0001 \\
\hline & Leucocytozoan & 1 & 1.09 & 384 & 69.01 & - & - & - \\
\hline & Ectoparasite & 1 & 1.09 & 100 & 0.31 & - & - & - \\
\hline & Histomoniasis & 1 & 1.09 & 101 & 0.09 & - & - & - \\
\hline & Chlamydiosis & 2 & 2.19 & 691 & $\begin{array}{l}12.9(10- \\
15)\end{array}$ & 0 & 0 & 0.38 \\
\hline
\end{tabular}




\begin{tabular}{|lllllll|}
\hline Total & 91 & 102643 & & & \\
\hline Continent & $\begin{array}{l}\text { No. of } \\
\text { publications }\end{array}$ & $\begin{array}{l}\text { Proportion of } \\
\text { publications }\end{array}$ & $\begin{array}{l}\text { Pooled prevalence } \\
(95 \% \text { Cl) }\end{array}$ & $\begin{array}{l}\mathrm{I}^{2} \\
(\%)\end{array}$ & $\mathrm{T}^{2}$ & $\mathrm{P}$ \\
\hline Asia & 13 & 23.6 & $32(17.9-48)$ & 99.7 & 0.089 & 0 \\
\hline Africa & 19 & 34.54 & $24.5(15.2-35.2)$ & 99.9 & 0.066 & 0 \\
\hline Europe & 5 & 9.09 & $26.3(5.3-55)$ & 99.8 & 0.118 & 0 \\
\hline $\begin{array}{l}\text { North } \\
\text { America }\end{array}$ & 5 & 9.09 & $23.9(3.3-54)$ & 99.5 & 0.133 & 0.0001 \\
$\begin{array}{l}\text { South } \\
\text { America }\end{array}$ & 8 & 14.54 & $17.7(3.8-38.4)$ & 99.8 & 0.111 & 0 \\
\hline Oceania & 5 & 9.09 & $30.6(7.1-61)$ & 99.2 & 0.125 & 0.0001 \\
\hline
\end{tabular}

Total no. of publications- 55

\section{Figures}

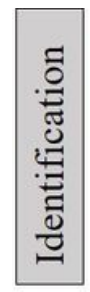

Records identified through electronic database search with combination of keywords

Pubmed (368), Biomed (81), Google Scholar (320)
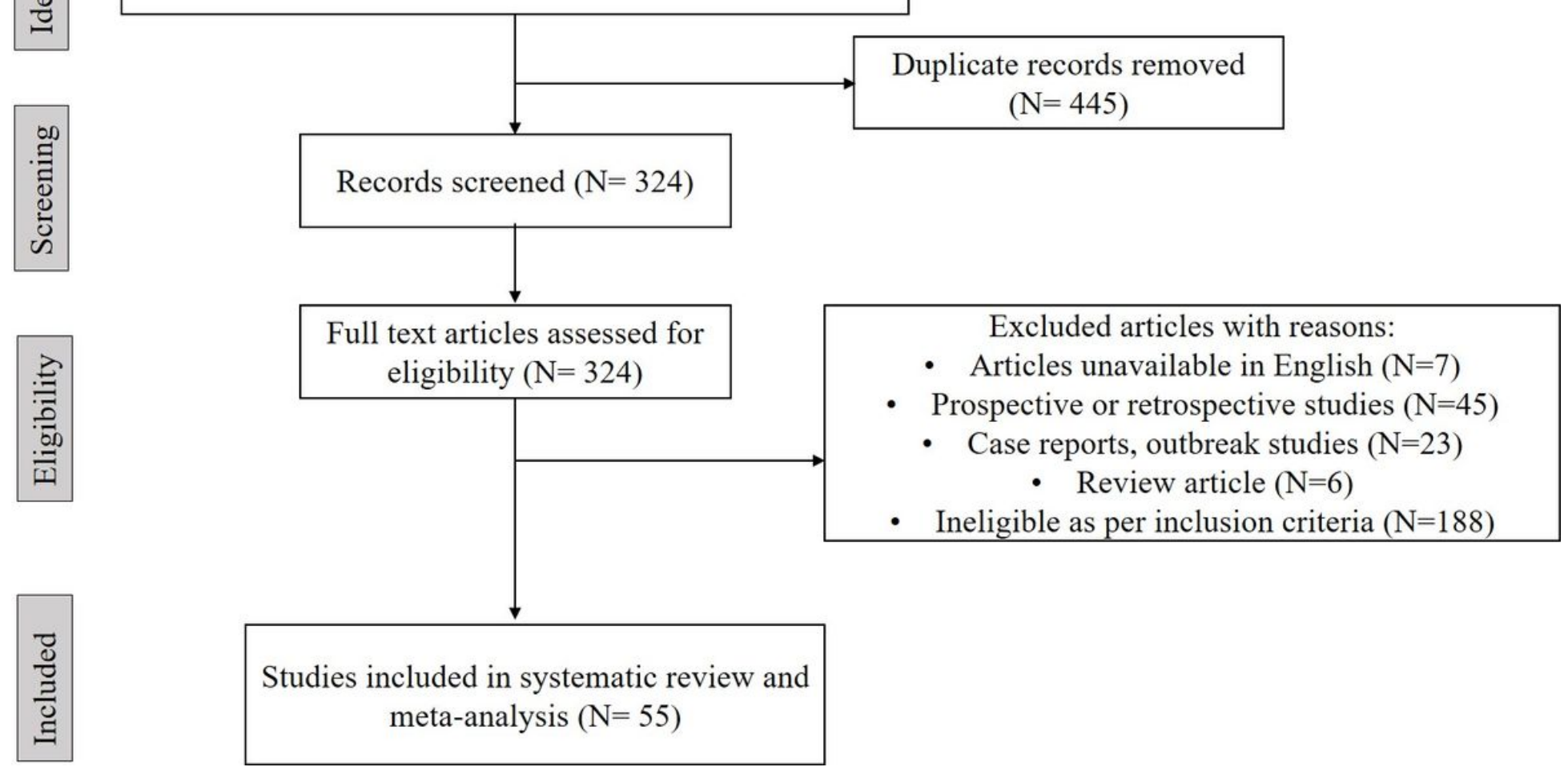

Figure 1

Flowchart illustrating the selection and inclusion of publications for systematic review. 


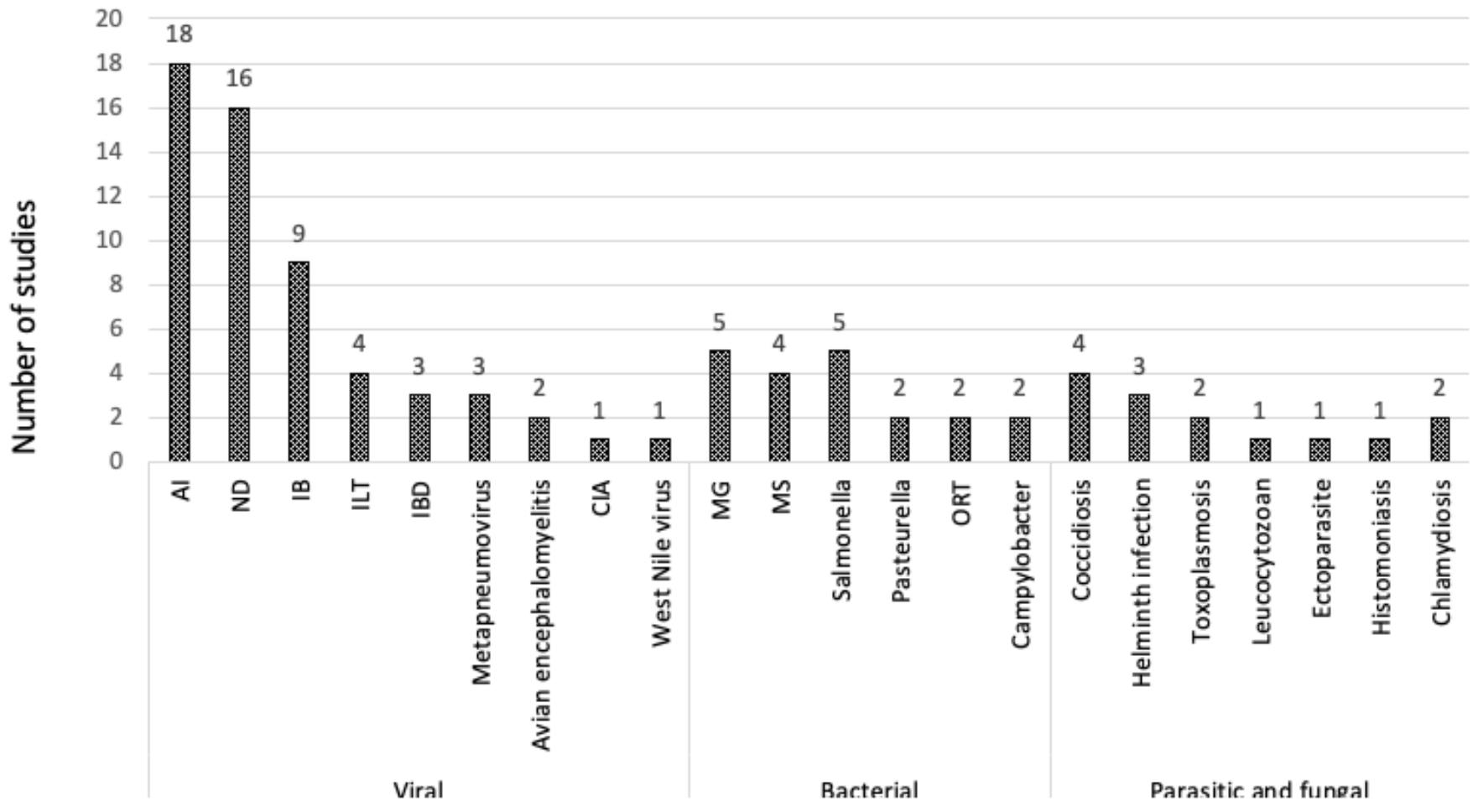

No. of studies - 91. AI: Avian influenza, ND-Newcastle disease, IB-Infectious bronchitis, ILT-Infectious laryngotracheitis, IBD-Infectious bursal disease, CIA-Chicken infectious anemia, MG-Mycoplasma gallisepticum, MS-Mycoplasma Synoviae, ORT-Ornithobacterium rhinotracheale.

Figure 2

Proportion of number of studies sorted by disease category wise (viral, bacterial and parasitic \& fungal). 


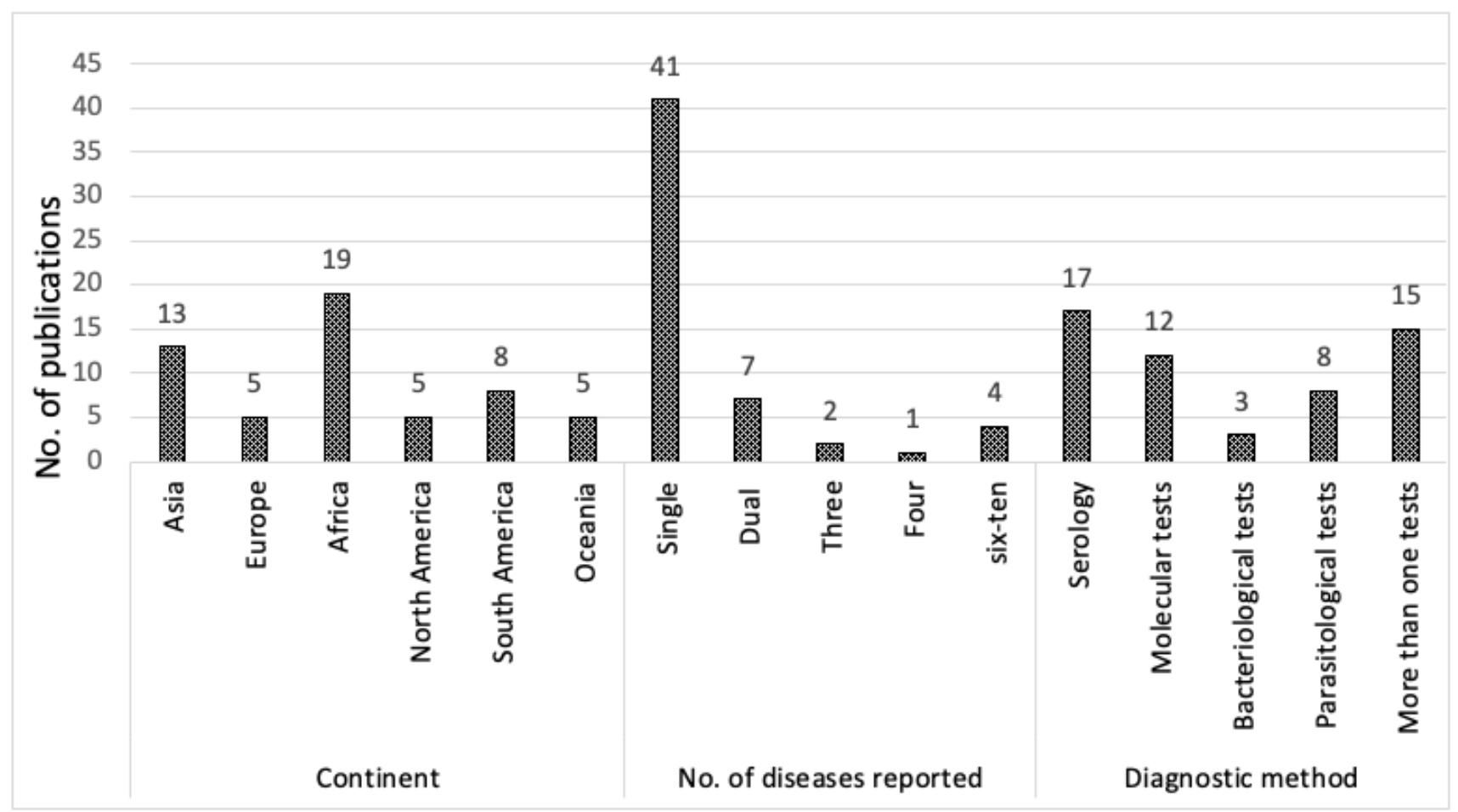

\section{Total no. of publications-55}

\section{Figure 3}

Proportion of the number of publications sorted by continent-wise, reported no. of diseases in each publication and diagnostic method used in the study. 
10

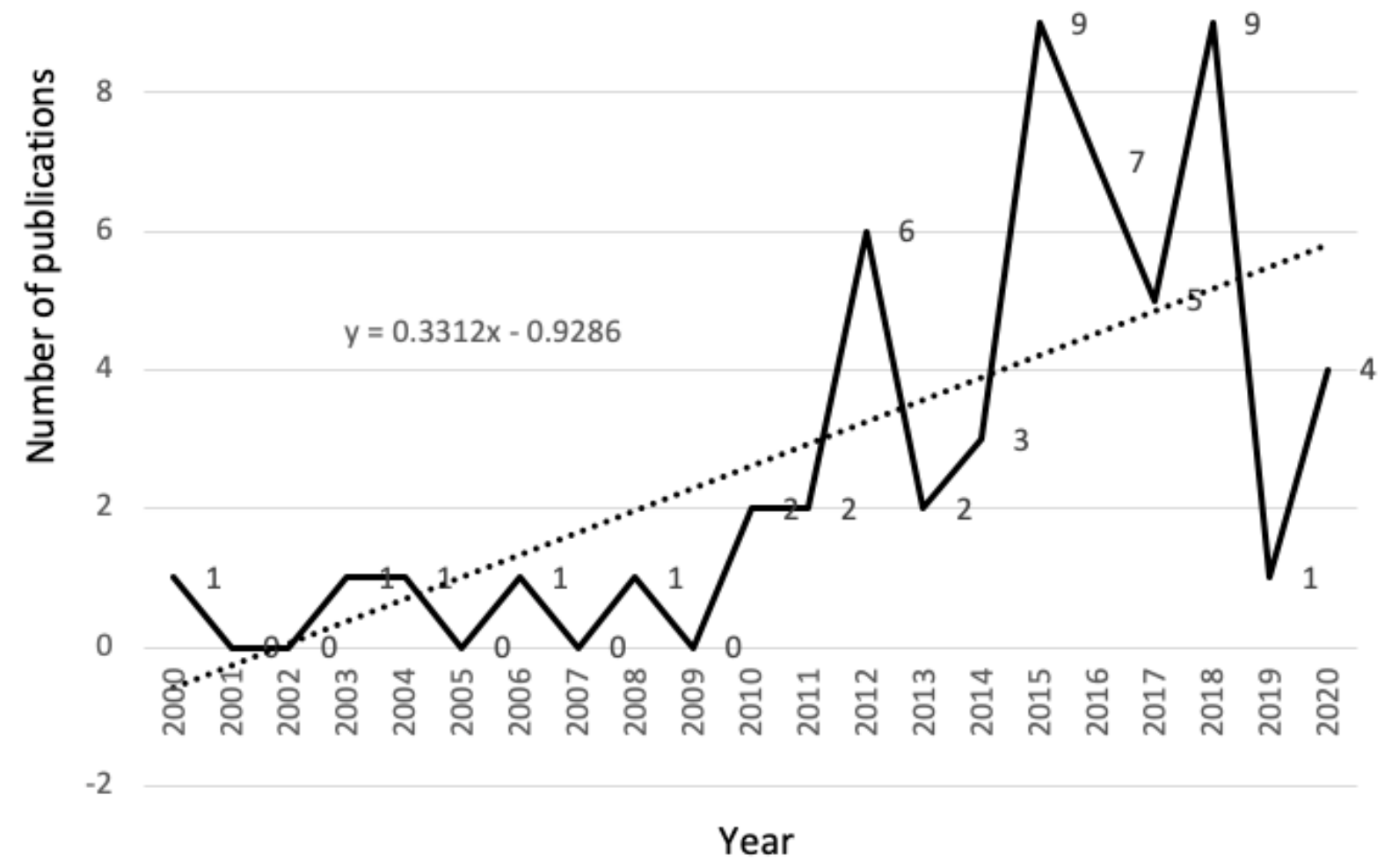

Figure 4

Trend of publications on prevalence of diseases in backyard chicken over the years. 


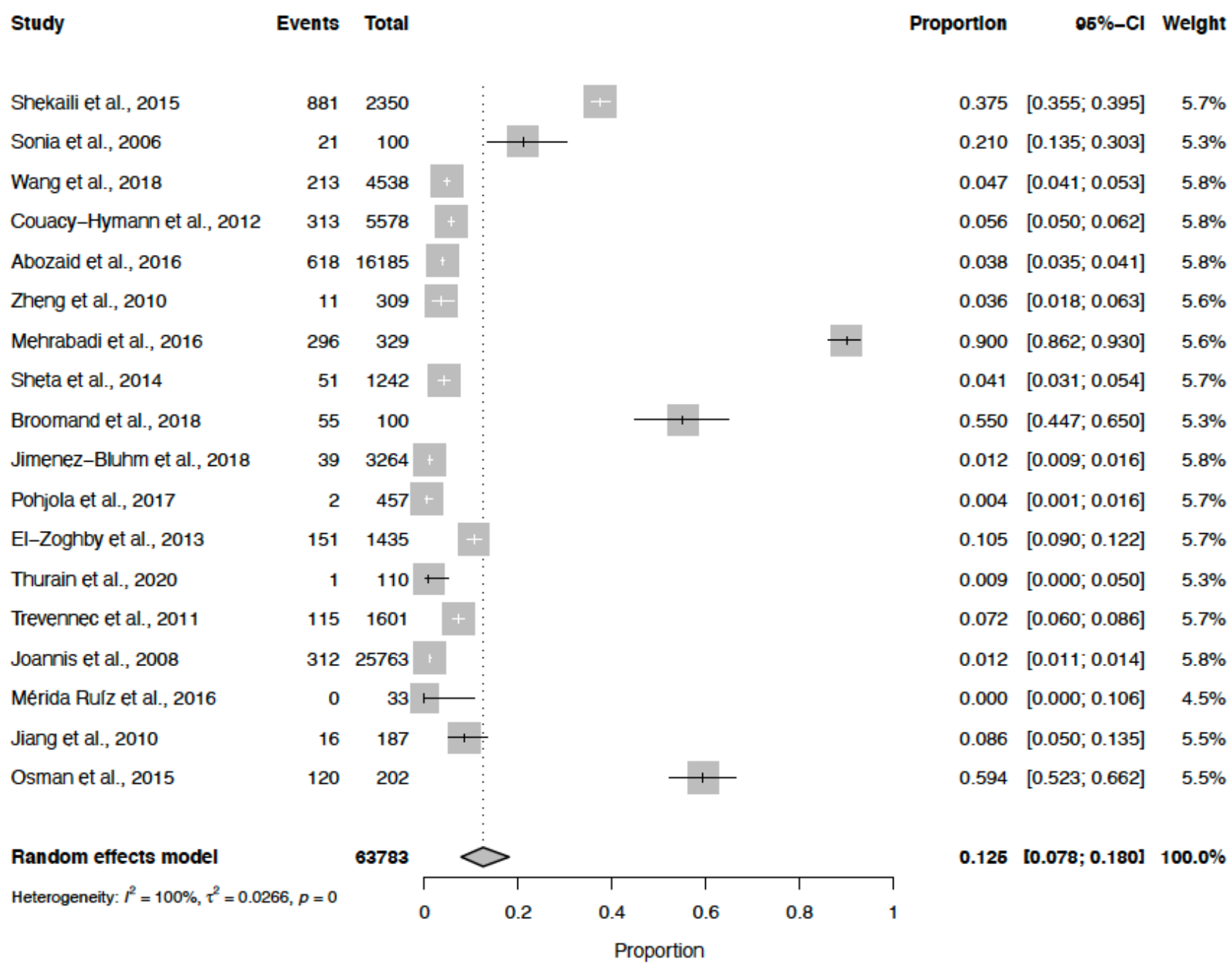

\section{Figure 5}

Forest plot of Avian influenza pooled prevalence. ES-Effective estimate. 


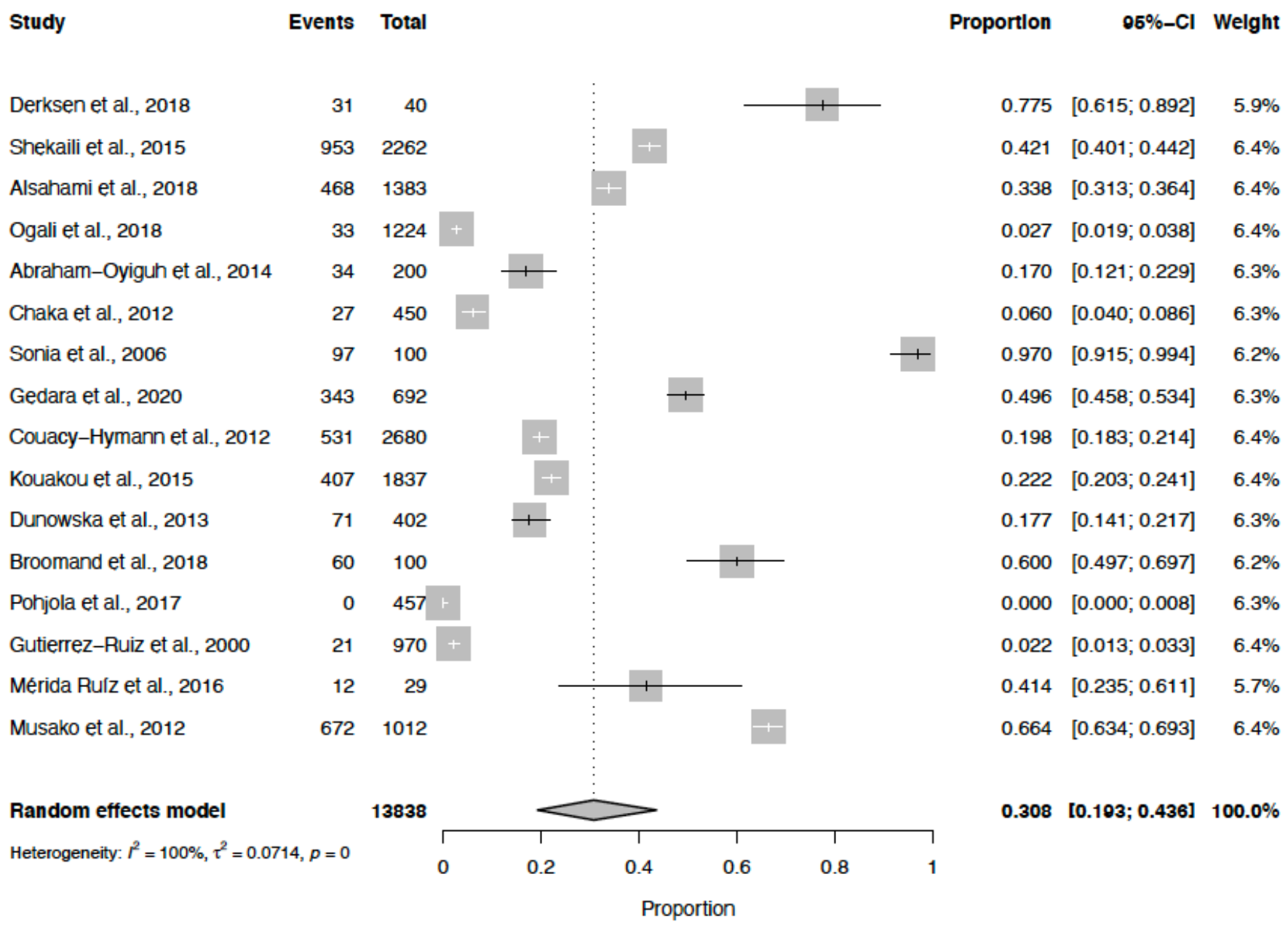

\section{Figure 6}

Forest plot of Newcastle disease pooled prevalence. ES-Effective estimate. 

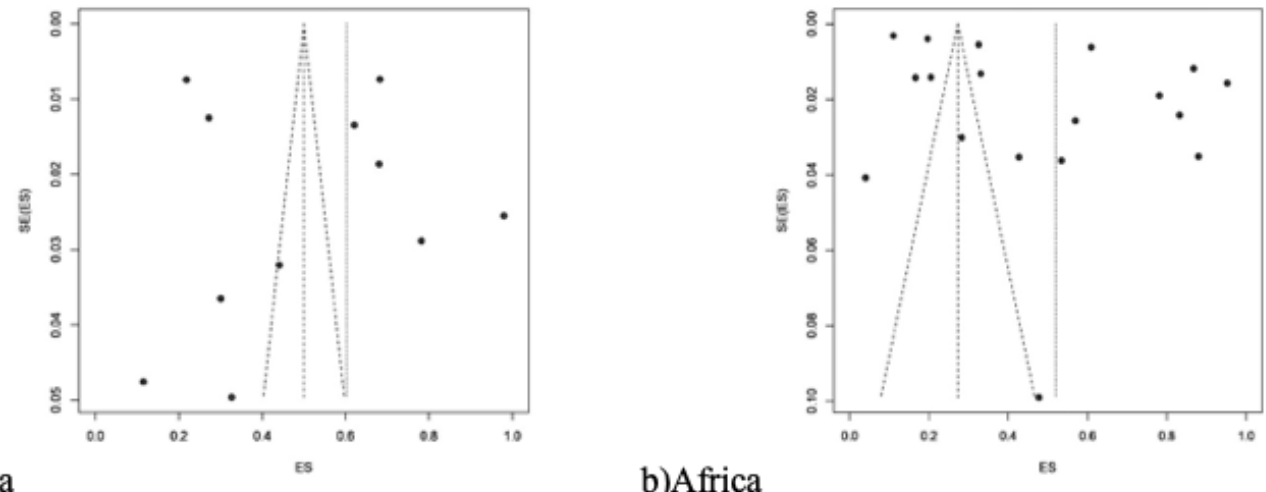

a)Asia

b)Africa

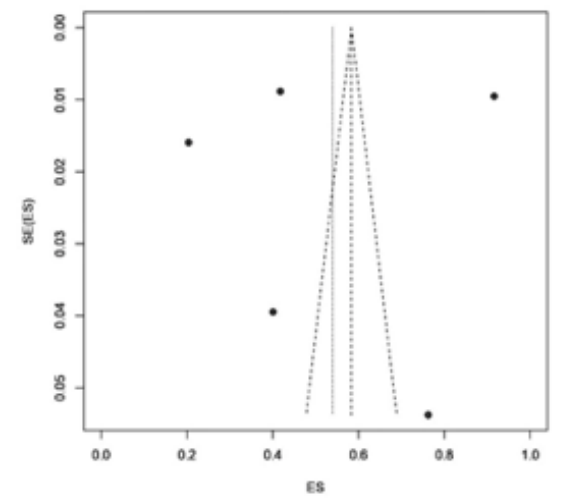

c) Europe

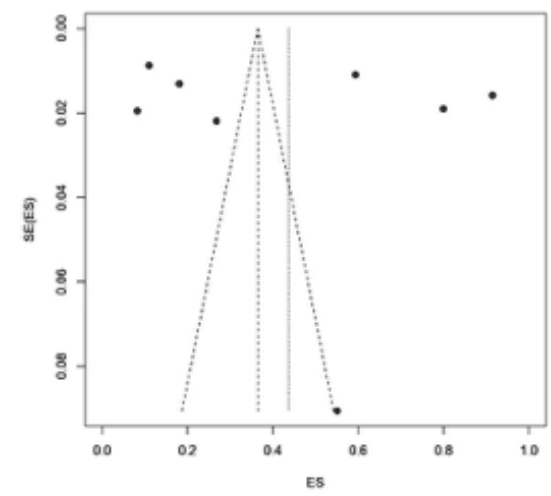

e) South America

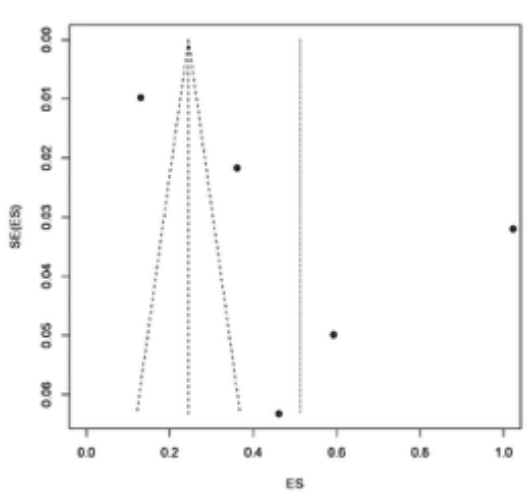

d) North America

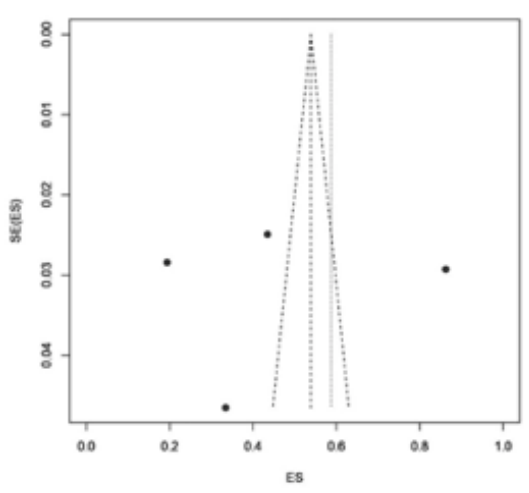

f) Oceania

\section{Figure 7}

Funnel plots of pooled prevalence estimates of coontinents a) Asia b) Africa c) Europe d) North America e) South America f) Oceania

\section{Supplementary Files}

This is a list of supplementary files associated with this preprint. Click to download.

- Supplementaryfile1.docx 
- Supplementaryfile2.docx

- Supplementaryfile3.docx

- Supplementaryfile4.docx 